\title{
A Fuzzy-algorithm-based Sliding Mode Control Approach for Acceleration Slip Regulation of Battery Electric Vehicle
}

Lin He ( $\nabla$ helin@hfut.edu.cn )

Hefei University of Technology https://orcid.org/0000-0003-3102-2520

Cheng Yao

Hefei University of Technology of Automotive Research Institute

Zejia He

Hefei University of Technology

Bingzhao Gao

Jilin University

\section{Qin Shi}

Hefei University of Technology

\section{Original Article}

Keywords: Electric motor, wheel slip, slip ratio, fuzzy algorithm, robustness analysis

Posted Date: December 18th, 2020

DOI: https://doi.org/10.21203/rs.3.rs-127653/v1

License: (c) (i) This work is licensed under a Creative Commons Attribution 4.0 International License. Read Full License 


\section{Abstract}

Due to large torque and quick response of electric motor, the traction wheels of battery electric vehicle (BEV) are easy to slip during the initial phase of starting. In this paper, an acceleration slip regulation approach based on sliding mode control algorithm is proposed to prevent the wheel slip of BEV. The traction wheel slip ratio is used as the control parameter, and a sliding mode controller is deduced from it. A fuzzy algorithm is employed to revise the switch function of sliding mode controller. After stability and robustness analysis, the sliding mode controller is validated by dynamic simulation of BEV. The sliding mode control law is transferred into vehicle control unit and is veried by road tests, the results of which show that the sliding mode controller is a good candidate to prevent the wheel slip.

\section{Full Text}

This preprint is available for download as a PDF.

\section{Figures}

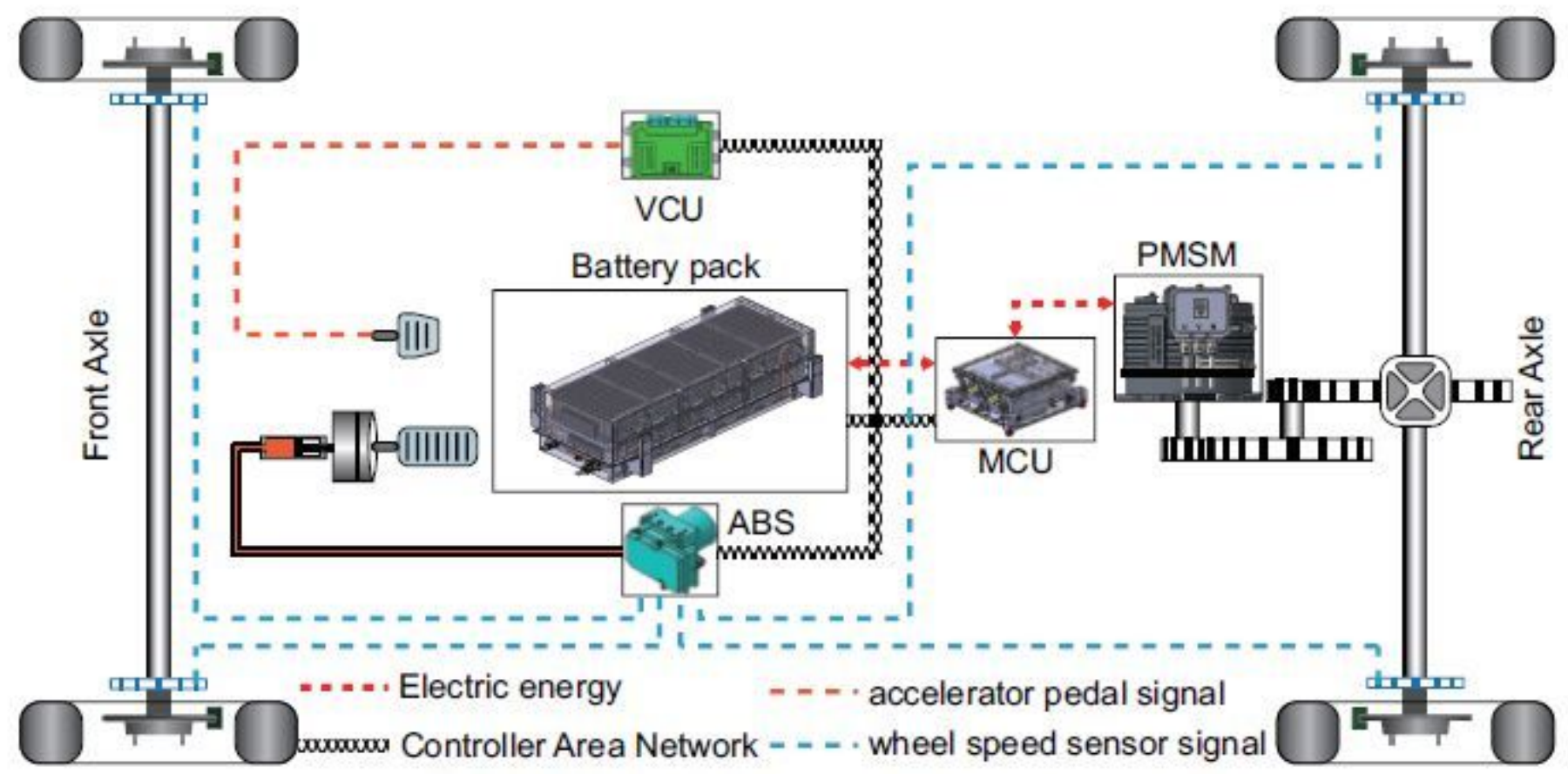

Figure 1

Vehicle architecture 


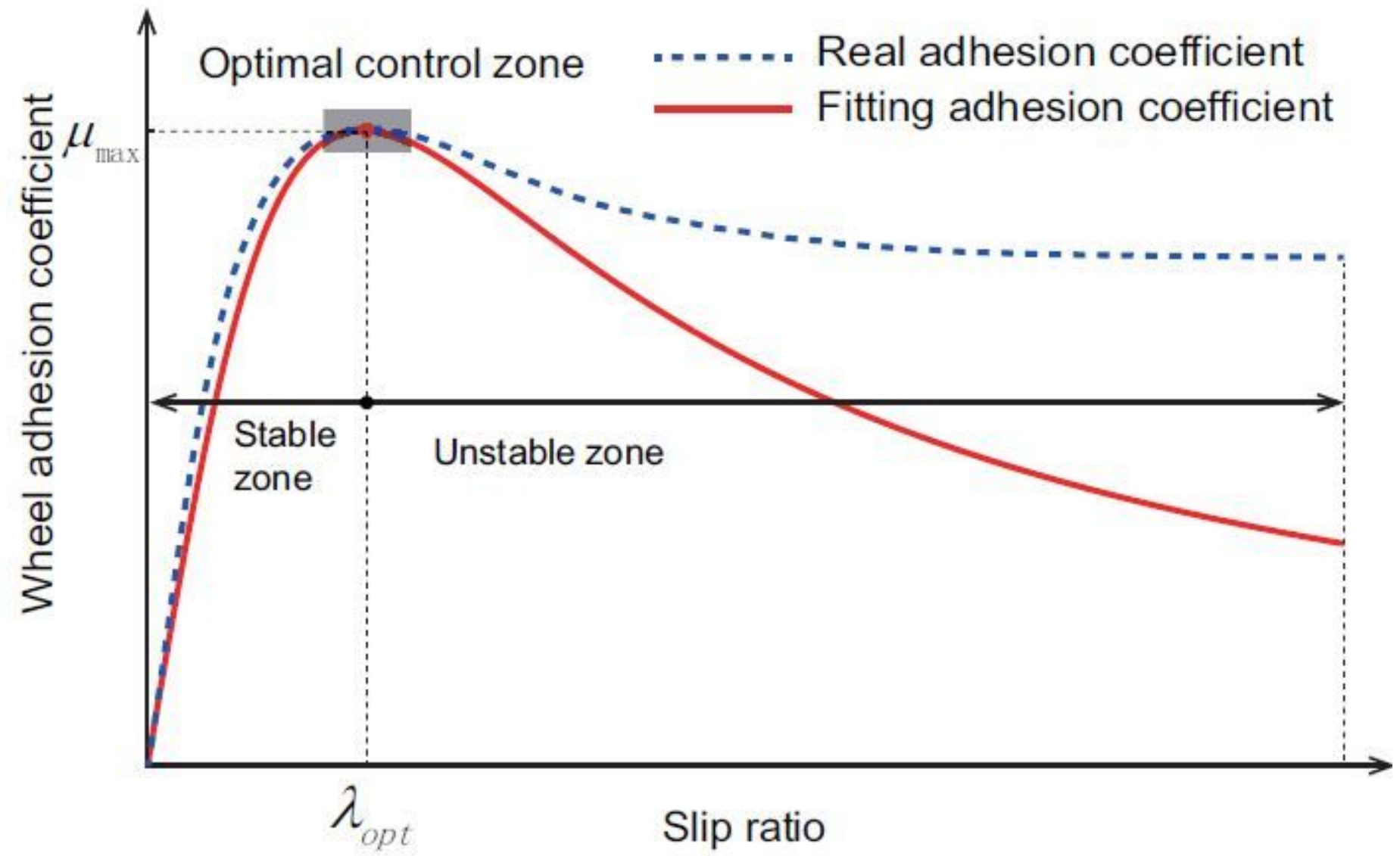

Figure 2

Adhesion coefficient 


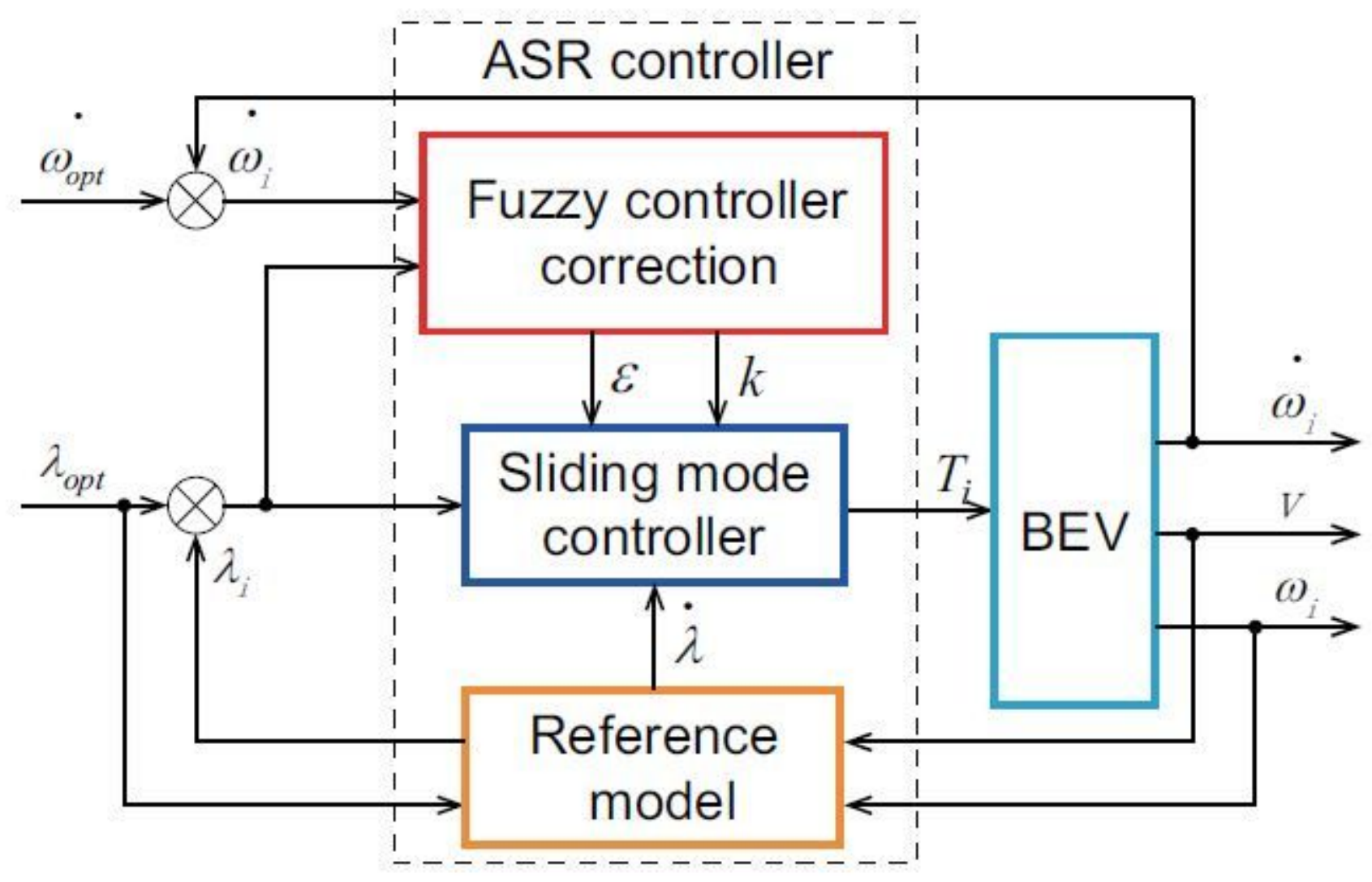

Figure 3

Structure of the ASR controller 


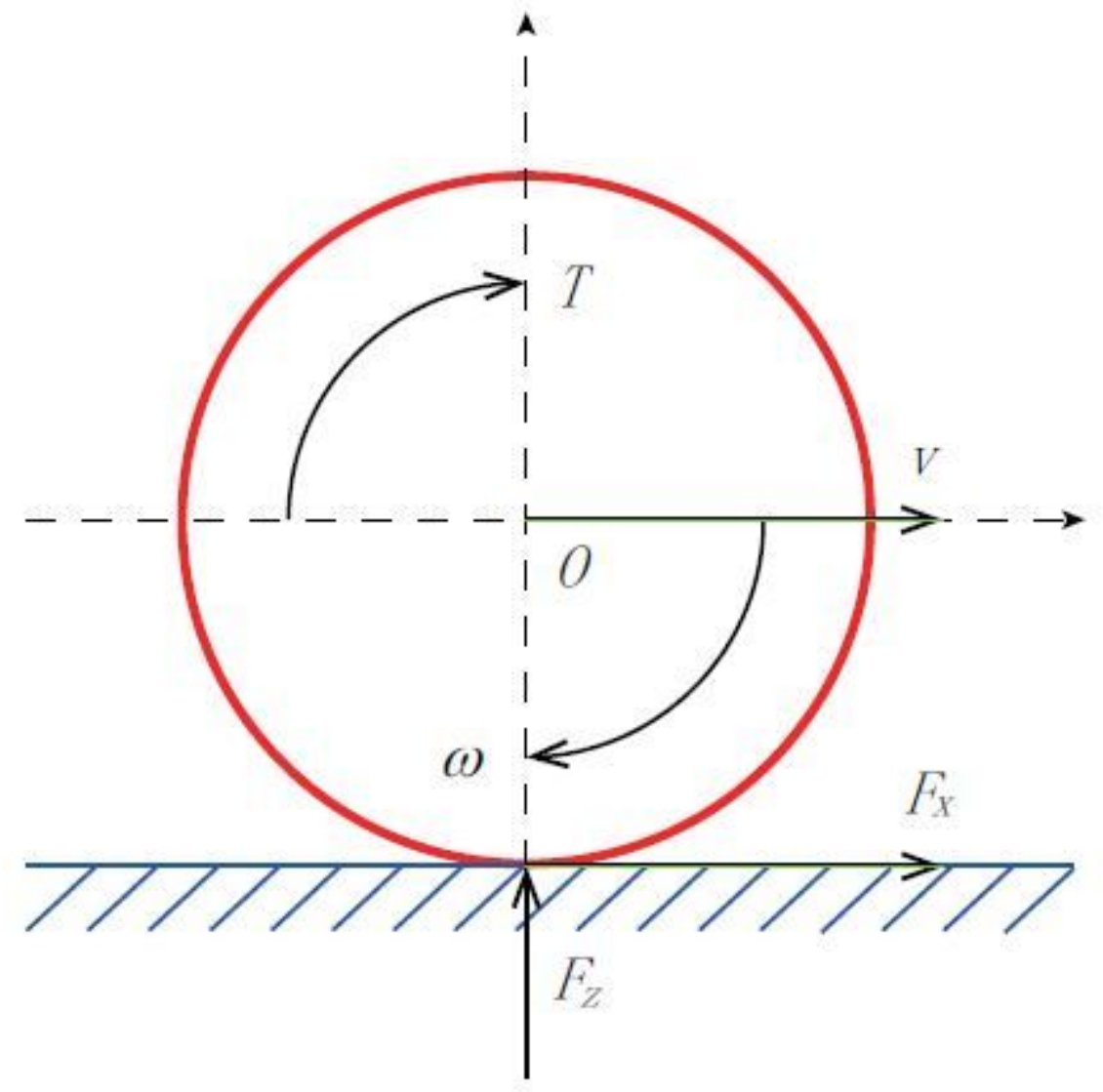

Figure 4

Single wheel model 


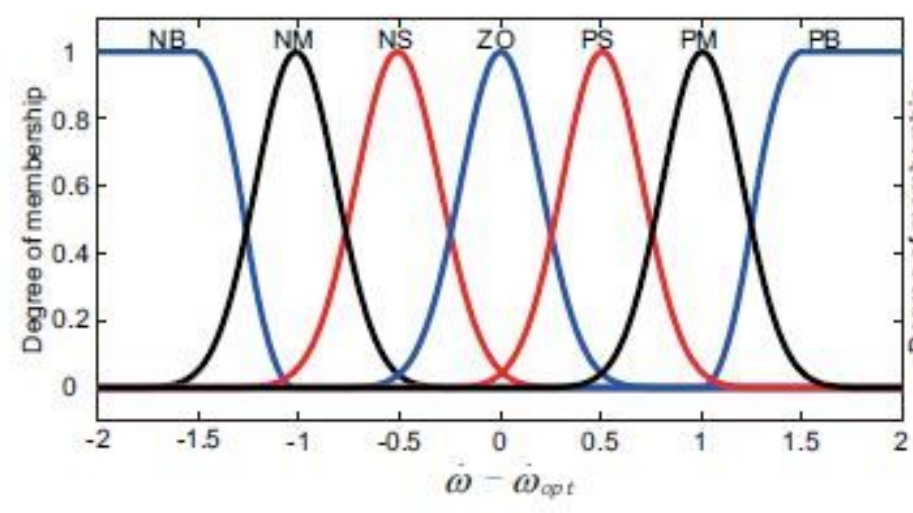

(a)

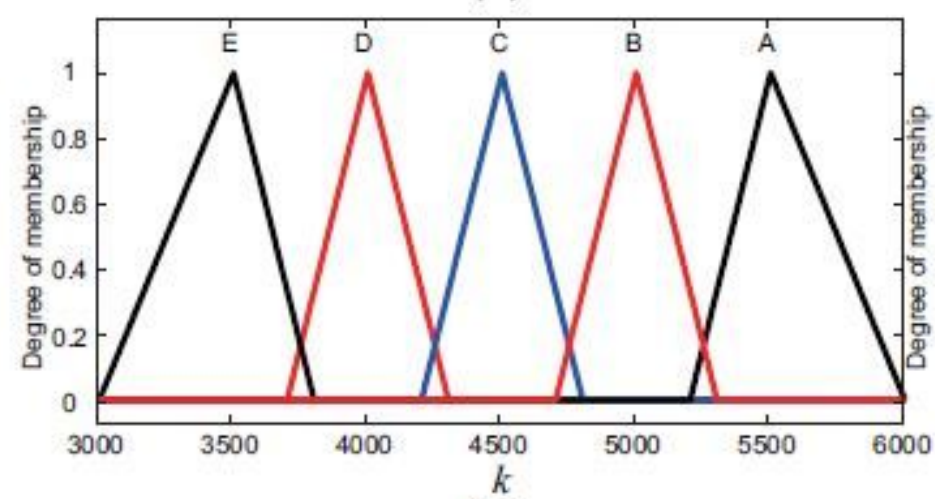

(c)

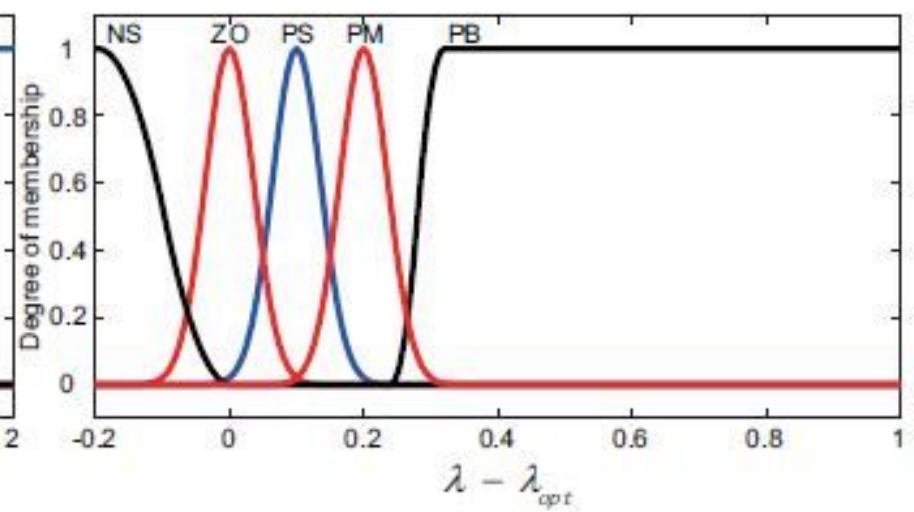

(b)

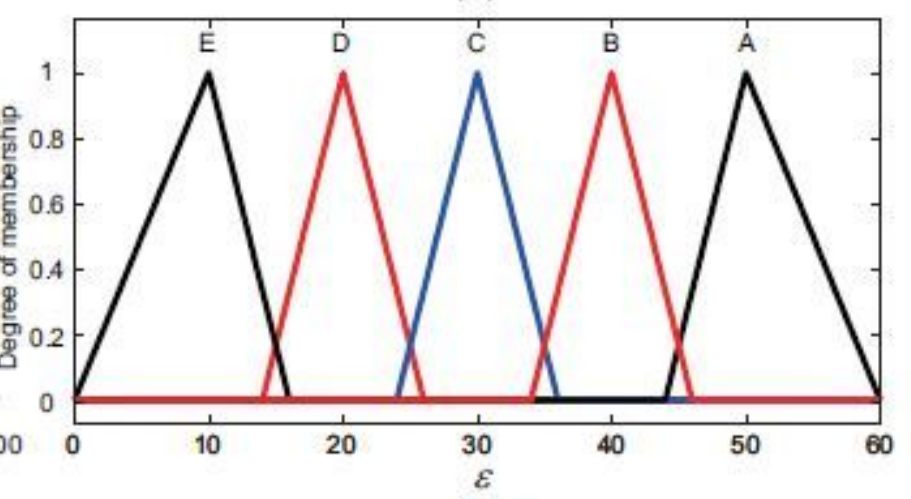

(d)

Figure 5

Membership function of variables 


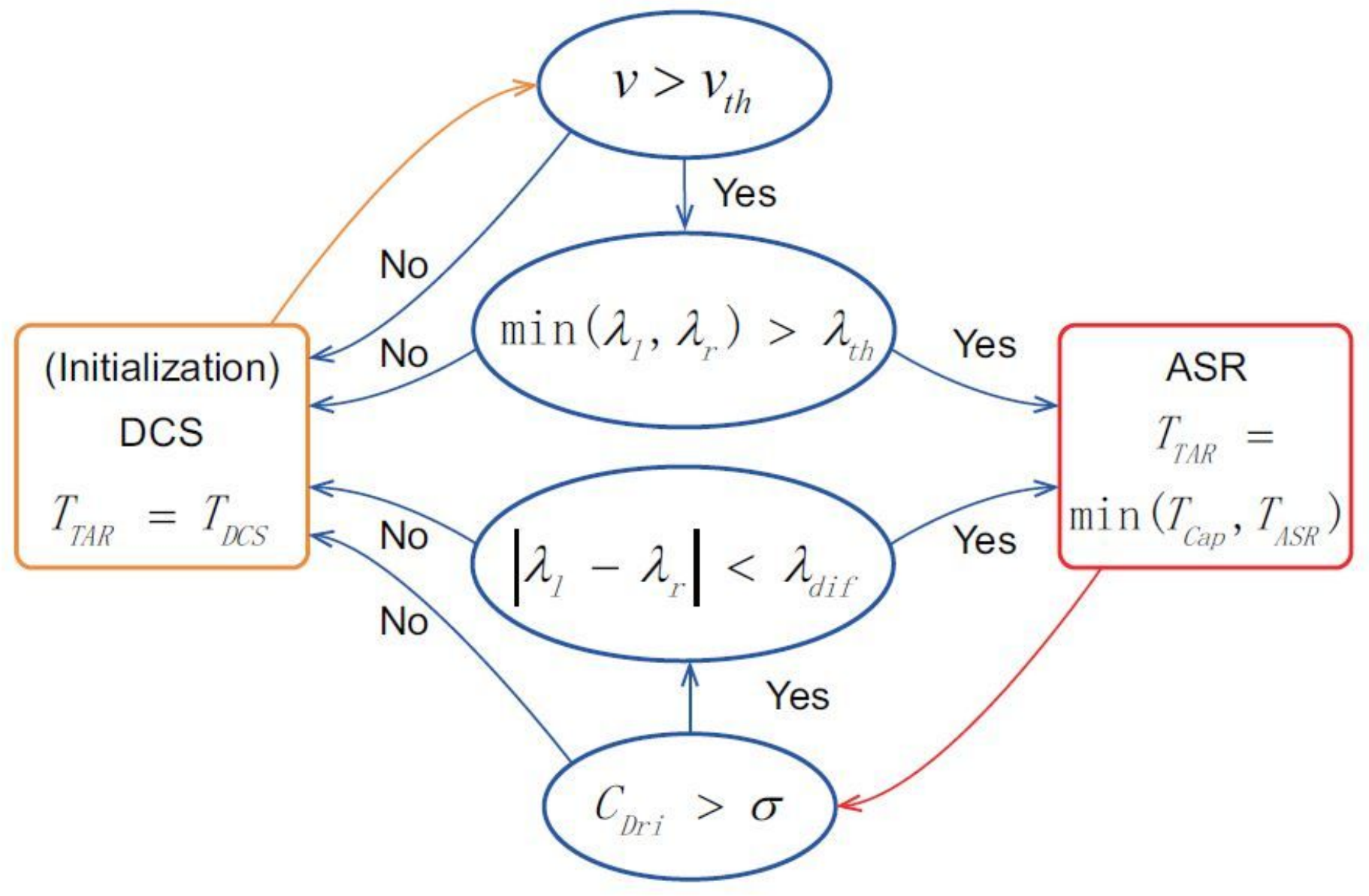

Figure 6

Control approach 


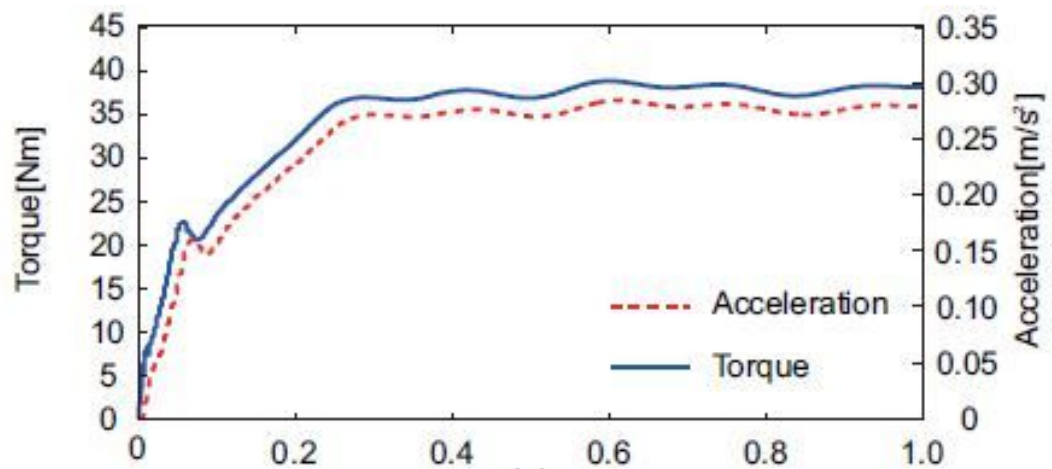

(a)
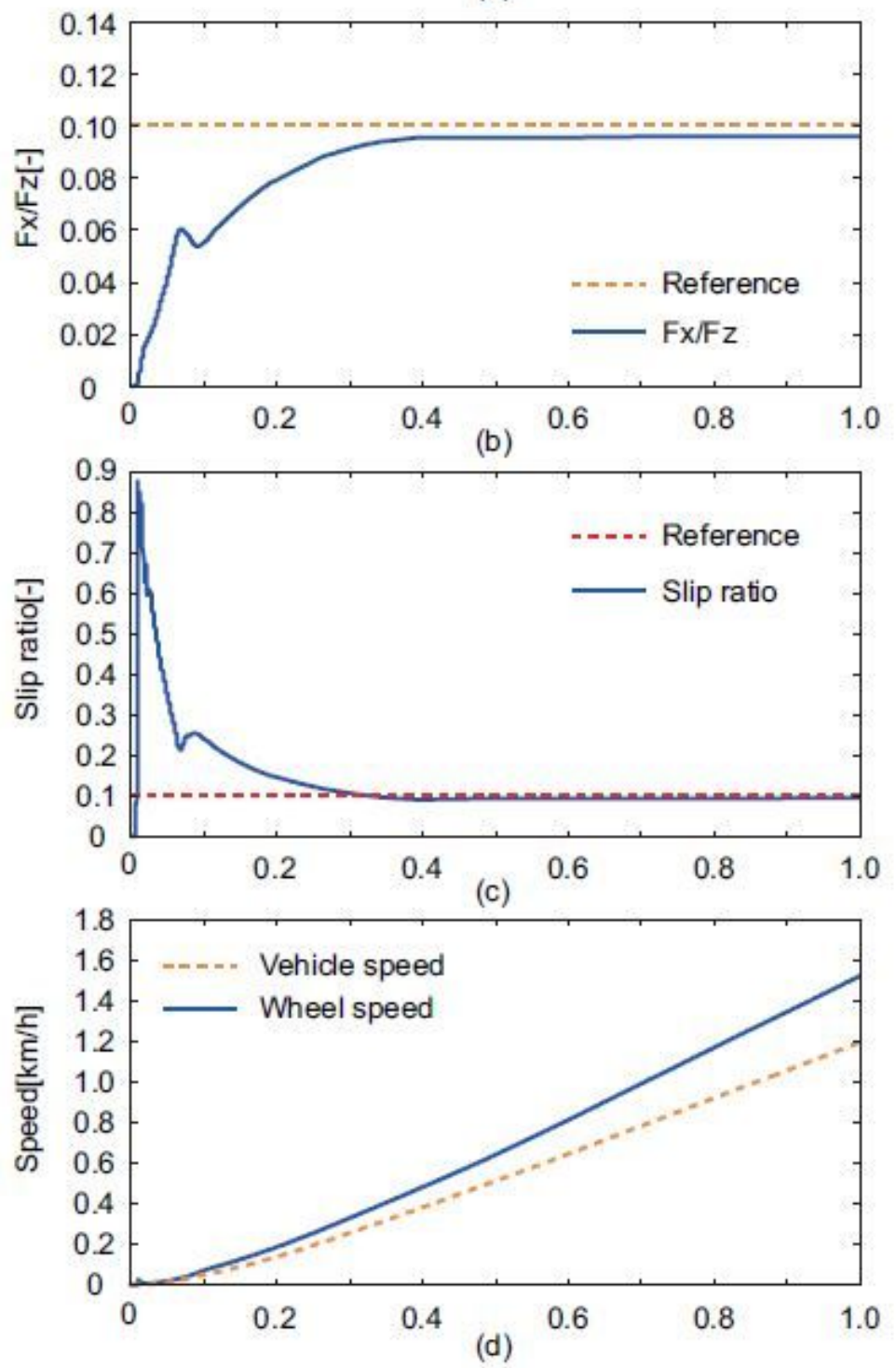

Time(s)

Figure 7

Simulation results of low adhesion conditions 


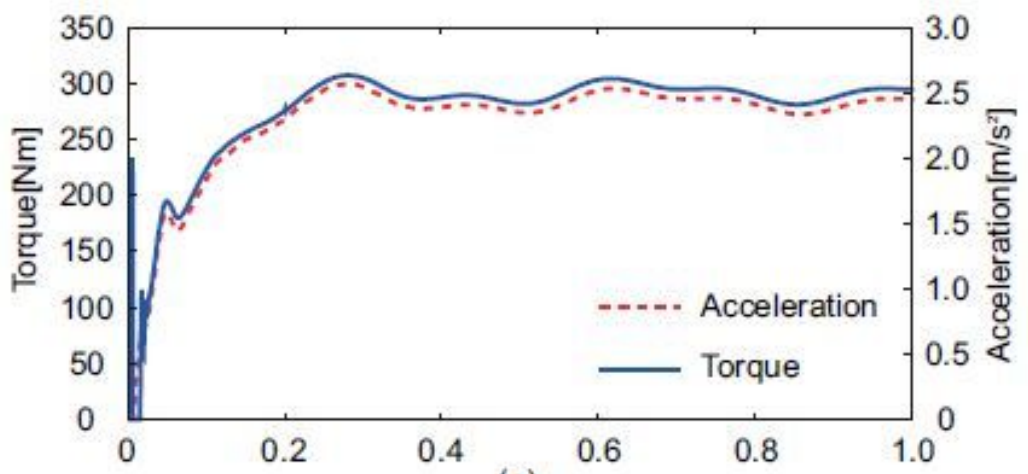

(a)

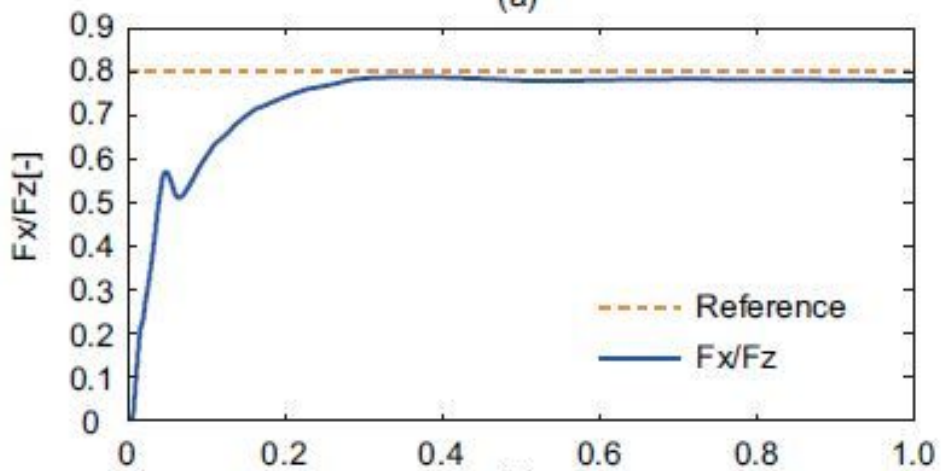

(b)

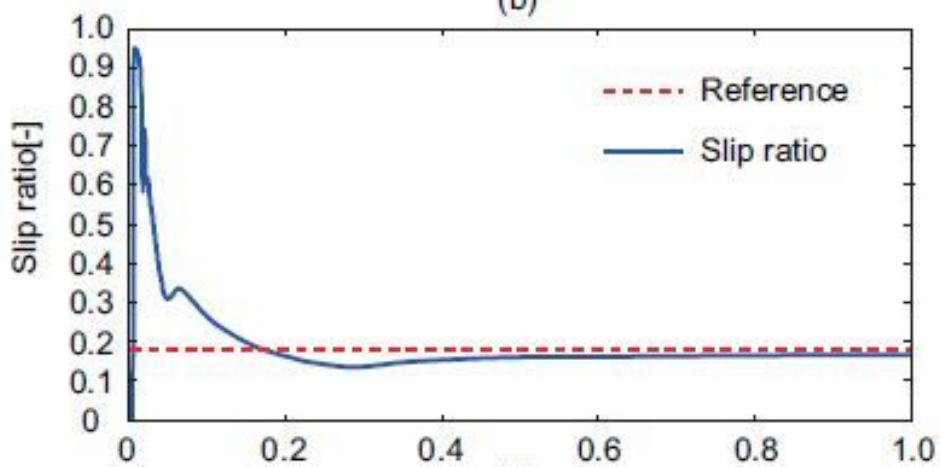

(c)

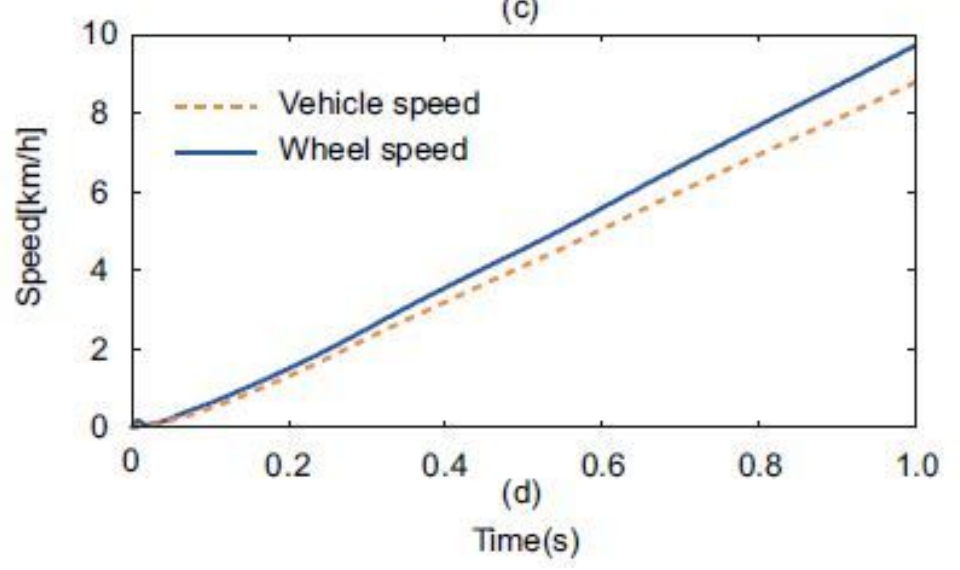

Figure 8

Simulation results of high adhesion conditions 


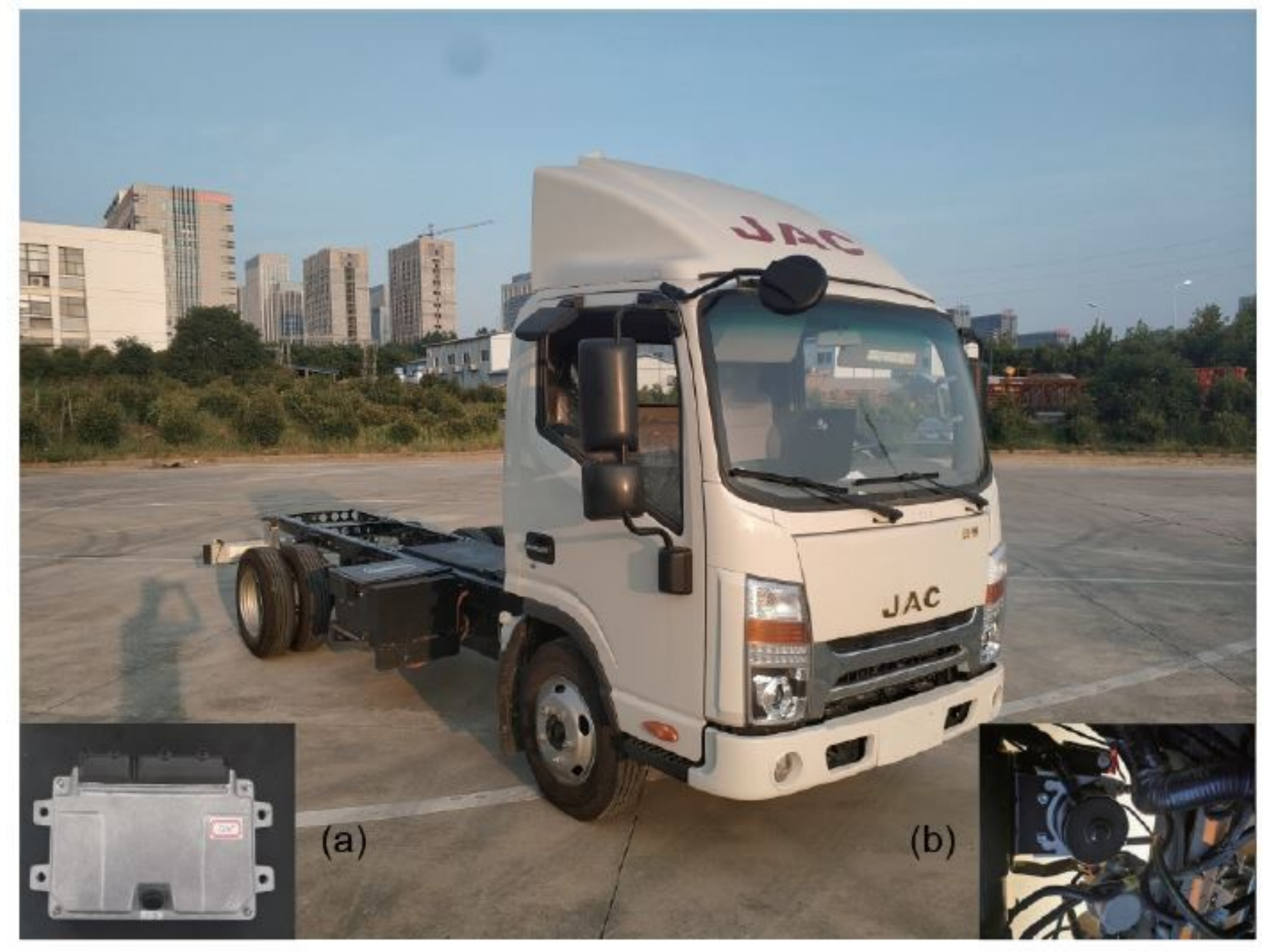

Figure 9

Test platform: (a) VCU; (b) ABS. 


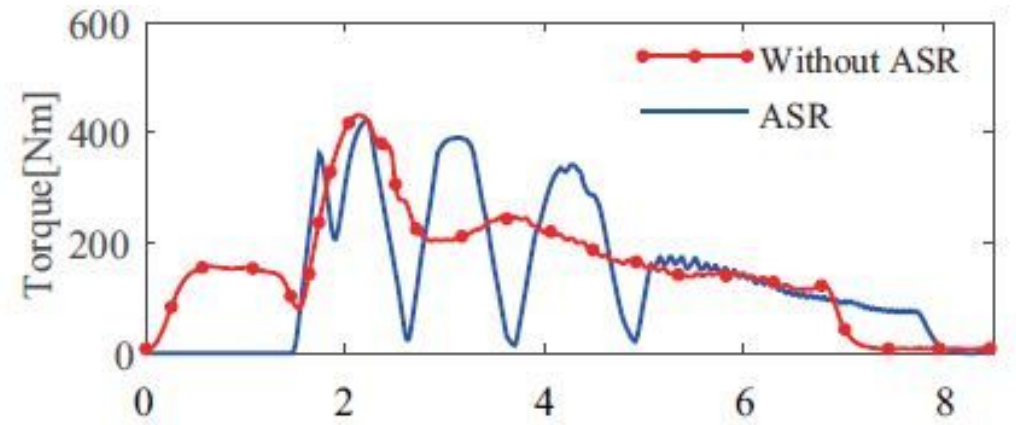

(a)

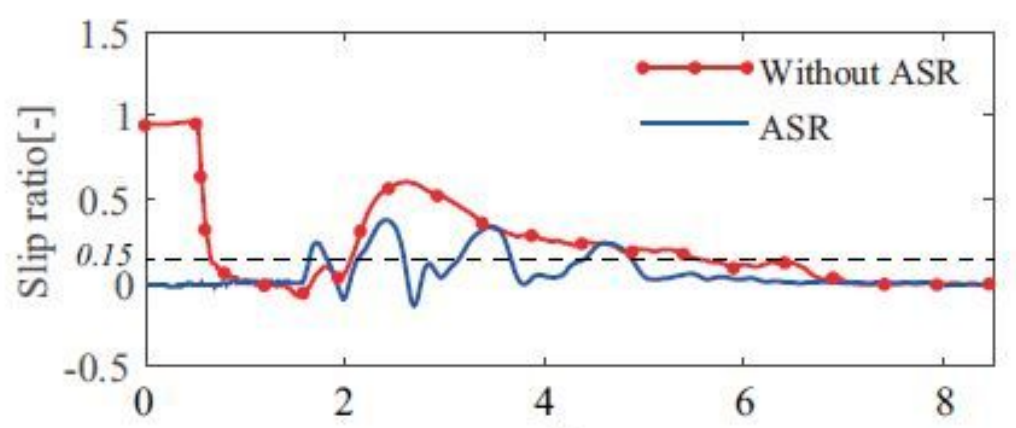

(b)

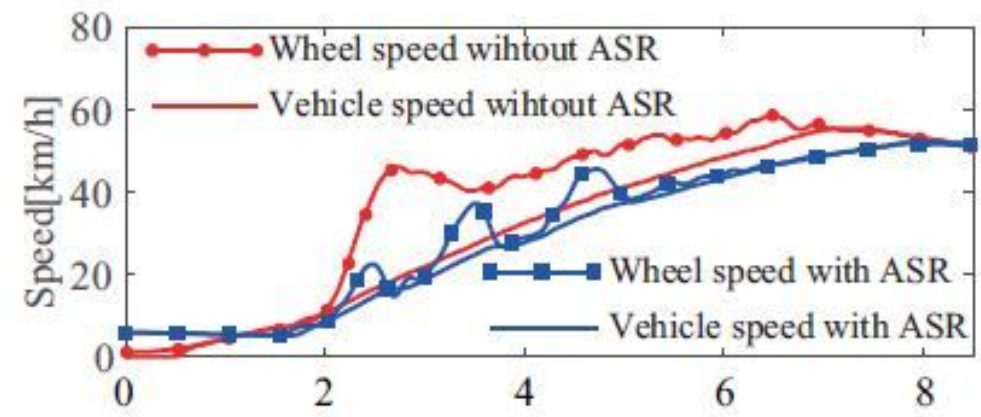

(c)

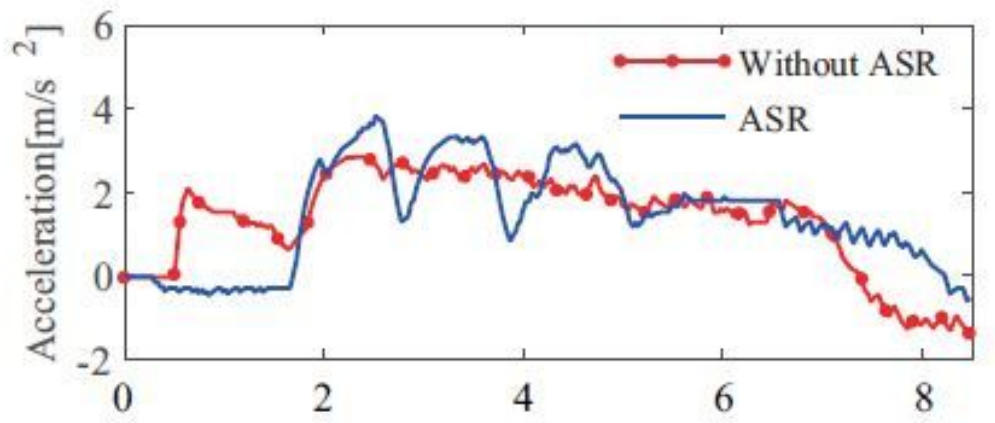

(d)

Time(s)

Figure 10

Vehicle test on dry road condition

\section{Supplementary Files}

This is a list of supplementary files associated with this preprint. Click to download. 
- datawithasr.xls

- WithASR.mp4

- WithoutASR.mp4

- datawithoutasr.xls 